\title{
Quo vadis and where are we going - (from the nineteenth century to the twenty-first century)
}

\section{Opinion}

When we now look at treatment facilities and therapy for the addicted and the development of public mental health care services in the nineteenth century in Canada and the United States of America in many ways, it is not a pretty picture, yet if we look carefully we note that new ideas came to fruition by progressive medical professionals from Europe and the United States, but neither the political will nor the economic capacity was yet harnessed to put these new principles into practice.

Yet progressive minded social activists were to be found in the USA and Canada. In the USA 1810 Dr. Benjamin Rush called for creation of a "Sober House" for the care of the confirmed alcoholic in the USA and in Canada the social reformer Bengough, John Wilson.

Further we note that as soon as new facilities were constructed according to the up-to-date asylum concepts, they became overcrowded. This large number of patients being stuffed into these early facilities marks not merely an increase in the general population or an epidemic of lunacy in the emerging nation of Canada, but a new awareness of mental illnesses as separate pathological conditions requiring new kinds of treatment and public protection. At the same time, unfortunately, the public, through their elected and appointed officials, were not capable of keeping abreast of these new needs.

On the one hand, it would be easy to dismiss it all as due to stingy governments, backwards thinking colonial and provincial officials, and frustrated health professionals. But laying blame only serves to polarize the issues, making it more difficult to combat this intransigence and trance-like resistance. Rather, as health professionals with experience in the care and treatment of the mentally ill, it is our duty to analyze these issues and try to contribute to the solution rather than adding to the problem.

History teaches us that societies often operate against their own best interests, but one has to assume that the people, who were there, believed that they were acting in their best interests whether on a group or individual level. The problem is that the best interests of the various stakeholders are usually different-often in conflict-so what is the best interest of one is often not in the best interests of another and setting one group against another in a political battle for control is almost never in the best interests of the mentally ill or of society as a whole. While all the Canadian institutions professed a moral treatment approach, overcrowding, the rather crude biological, psychological and social treatment methods of the time, and the lack of adequate resourceshuman, fiscal and physical-militated against humane institutional conditions by today's standards in all the provinces of Canada. But can one put all the blame on external conditions? Perhaps, as we have started to show, there are other kinds of explanation, reasons inside the mentality of the public, governments, and even the professionals
Volume 3 Issue 3 - 2017

\author{
Sam Sussman \\ Canada
}

Correspondence: Sam Sussman, Sabbatical now in Vancouver, Canada,Tel 604-90I-4982,

Emailsamsussman@physicianscanada.net

Received: April 08, 2017| Published: April 21, 2017

which resisted the newer ideas about the mind and the treatment of its illnesses already well advanced by 1914 .

In the mid-twentieth century, society was forced to recognize the inhumane conditions in the institutions which society had created to care for the mentally ill and especially the drug addicted. Institutionalization then gave way to deinstitutionalization and community care. As this author-Sussman- mentioned in an editorial in the British Medical journal twenty years ago (1997) that even though modern day psychiatry is empirically driven, biochemically oriented and by and large community committed and oriented, care can still be improved in the twenty first century whether it be in the community or in general hospitals. After 400 years of development and reform many are currently saying that, with all their flaws, psychiatric institutions provided relief and treatment to their patients whereas now phenomena such as incarceration and homelessness have replaced the psychiatric institution.

Despite this "progress ", homelessness, trans-institutionalization and an increase in mentally ill patients who find themselves in penal institutions are very much part of the overall mosaic of psychiatric services in Canada and in the United States of America. The political will and subsequent allocation of resources to fund an effective and consequently resource-rich community care system is problematic. Future generations will judge this system by its results and not by its good intentions.

Homelessness and trans-institutionalization in jails, and habitation in slums, which have become psychiatric ghettos does not augur well for this so called "community care" treatment modality. We can, however, hope!

\section{Acknowledgements}

None.

\section{Conflict of interest}

The author declares no conflict of interest. 